\title{
Getting to the Nitty-Gritty of Grit: A Descriptive Characterization of Gritty L2 Learners from Thailand, Malaysia, Taiwan and Japan
}

Mark R. Freiermuth, Gunma Prefectural Women's University

https://orcid.org/0000-0002-2463-2550 mark-f@fic.gpwu.ac.jp; markgunma@gmail.com

Latha Ravindran, UCSI University

https://orcid.org/0000-0002-5830-2437

latha@ucsiuniversity.edu.my; ravindranlatha70@gmail.com
Chomraj Patanasorn, Khon Kaen University

(iD https://orcid.org/0000-0003-4980-2795

chomraj@kku.ac.th; chomraj@hotmail.com

Hsin-chou Huang, National Taiwan Ocean University

https://orcid.org/0000-0002-0463-1198

joehuang@ntou.edu.tw; ntoumail2009@gmail.com

\begin{abstract}
Understanding the make-up of gritty L2 students has garnered quite a lot of attention recently. In this descriptive narrative-based study, we looked at the interview data of eight English language learners who recorded high scores on a nine-item grit questionnaire. Specifically, two female university students each from Taiwan, Malaysia, Thailand and Japan were interviewed and their interview scripts were transcribed and then coded looking for common threads to emerge from the data by applying the tenets of Charmaz's (2006) Grounded Theory. The data show that beyond perseverance, gritty L2 students enjoy learning the $\mathrm{L} 2$, are consistently curious about the L2, are generally not bored by the L2, are confident using the L2 (not letting anxiety dissuade them), are extraverted-encompassing a strong willingness to communicate, have focused L2 vision and have had experiences and/or encounters that bolstered their L2 grittiness. As for encouraging L2 grit development, we suggest that good L2 classroom practice include frequent communicative activities so that students can see the practical side of learning a L2 with the hopes of strengthening their L2 vision.
\end{abstract}

Keywords: grit, perseverance, curiosity, enjoyment, anxiety, boredom, extraversion versus introversion, willingness to communicate, L2 vision

This work is licensed under the Creative

Commons Attribution-ShareAlike 4.0

International agreement (CC BY-SA 4.0).

http://creativecommons.org/licenses/by-sa/4.0/
Journal for the Psychology of Language Learning

ISSN: 2642-7001

(2021) Volume 3, Issue 2, pp. 133-155 https://doi.org/10.52598/jpll/3/2/9 


\section{INTRODUCTION}

Psychology as it relates to language learning has focused attention on the individual differences that exist between learners, due in part to the belief that such differences affect students' L2 linguistic usage and behaviors (Freiermuth, 2020). Although there are a myriad of psychological constructs that affect language learners (motivation, willingness to communicate, anxiety, identity, emotion, etc.) they are generally conceptualized as being those that are affected by situation, implying that they may change dependent upon what the learner has encountered and those that are trait-like, implying that they show consistency across situations (Dewaele, 2012; Dewaele, 2014; Dewaele \& MacIntyre, 2016; Dörnyei \& Ryan, 2015; MacIntyre, Clément, Dörnyei, \& Noels, 1998). One personality trait that has gained significant traction recently is "grit," defined here as a strong commitment coupled with passion, determination and perseverance to obtain one's objectives (Duckworth, et al., 2007; Duckworth, 2013; Ericsson \& Charness, 1994; Howe, 1998). In the case of language learners, if they are indeed gritty, it should be reflected by their L2 behavior. Nevertheless, up to this point, language learning grit has been under-investigated, making this special issue of critical importance to further our understanding of the role grit plays in the lives of language learners (Teimouri, Plonsky \& Tabandeh, 2020). In this qualitative case study, we will examine interview data from female English language learners who had previously indicated their grittiness on a shortened version of the grit questionnaire (see Teimouri, Plonsky \& Tabandeh, 2020). Using a modified version of Charmaz's (2006) Grounded Theory, we analyzed discourse produced during these interviews to identify emergent categories of commonality.

\section{A Tale of Grit}

An anecdote about US army cadets during basic training, which was taken from an early chapter in Angela Duckworth's (2013) influential tome about the effects of grit-Grit: The Power of Passion and Perseveranceexplores the regimen and behavior of these elite soldiers in the making. Although the army cadets are considered the cream of the crop simply by their election into West Point, the physical, mental and emotional severity of the training quickly weeds out those who cannot cut it. The overall aim of the program, according to one cadet, is to expose a cadet's weaknesses with the ultimate goal of toughening the cadet - transforming a cadet into a soldier.

How does this relate to language learners? In our roles as L2 teachers and researchers, we encounter all sorts of L2 learners - like the West Point cadets in the vignette-who are affected by their physical surroundings and their own psychological perceptions of learning a language and all that this entails. Some do not succeed or experience very limited successes, while others push themselves to achieve one success after another. This paper, then, aims to identify those learners who seem not to waiver in their pursuit of learning English as a foreign language or as a lingua franca-those learners who have demonstrated their 'grittiness.' Besides identifying them as having grit (using an established grit questionnaire), our objective here is to peel back the surface knowledge by questioning them on a deeper level with the aim of developing profiles for gritty L2 learners in EFL and ELF setings (Freiermuth \& Ito, 2020; Teimouri, Plonsky \& Tabandeh, 2020). To create such profiles, we hope to identify some similarities among the L2 learners, which harmonize with their own reflections. To get to that point, we will first operationalize grit for our purposes and then discuss various research findings aimed at measuring what elements may affect grit; we then provide the procedures we applied to gather our data and finally, we take our results and discuss the meaning behind each prevalent factor raised during the interview process.

\section{The Nitty-gritty of L2 Grit}

The story of the army cadets was introduced here because it provides some perspective. Duckworth (2013) tested an assessment tool to measure the grit of cadets at West Point basic training. Interestingly, she found that a cadet's grittiness was the determining factor for success-not leadership, not athletic ability and more importantly when considering the case of language learners neither talent nor straight-up intelligence. She also looked at sales professionals and found that grit was the key to their successes as well-not personality traits such as extraversion, emotional stability or conscientiousness (see Dewaele, 2012 for a thorough discussion of personality traits in L2 learning). Hence, we are faced with the real possibility that the personality trait of grit-a self- 
regulatory, non-cognitive trait - may also be a fundamental key in the success of language learners as well (Duckworth, Peterson, Matthews \& Kelly, 2007).

\section{LITERATURE REVIEW}

When we look at language learners and their L2 learning trajectories, we are confronted with the notion that they either have natural abilities - the so called language aptitude - to learn a language or that they have to exert a certain amount of effort to be successful (Dörnyei \& Skehan, 2003; Skehan, 1998; 2002). Although there is sufficient evidence that some L2 learners possess more 'talent' for learning language than others (Dörnyei \& Ryan, 2015), like the army cadets from Duckworth's (2013) book, it is hard to give credence to the idea that without a decided upon concerted effort along with a steadfast determination, L2 learning would succeed to any relevant degree. Hence, when gritty L2 learners encounter obstacles of various shapes and sizes, which may derail other learners, they must be able to overcome those challenges to achieve their objectives (Dörnyei \& Ryan, 2015; Pawlak, 2011). As such, we too need to consider 'grit' as an important psychologically-based construct warranting extensive L2 research (Costa \& McCrae, 2008). Additionally, in spite of the potential magnitude of the role that grit may play in L2 learning, there has been a noticeable lack of attention given to it.

\section{Potential Factors Affecting Gritty L2 Learners}

In this section, we will review some researched factors which are potentially interconnected to L2 grit, namely curiosity, emotions (anxiety and enjoyment), boredom, extraversion (encompassing WTC as a behavioral aspect of extraversion, see Dewaele \& Furnham, 2002) as well as introversion, past experiences, personal encounters (which also reflects WTC) and L2 vision.

Successful L2 learning involves more than a learner simply deciding to learn a language; it also involves action and more importantly perseverance (Williams \& Burden, 1997), which is considered a key component of grit. In addition, perseverance in L2 learning is often associated with a learner's vision and the translating of that vision into perpetual behaviors, which can somehow be recharged to affect L2 growth positively (Dörnyei \& Kubanyiova, 2014). This idea is an extension of Dörnyei's (2009) research on possible L2 selves. When students have a plausible L2 'ideal' self-their own image of a successful language learner-they are able to translate their vision into durative, substantial and sustainable action. With this said, other factors must also contribute to L2 grittiness, so vision as well as other factors will be discussed in more detail henceforth.

L2 curiosity is one of those factors, which may affect gritty students as it tends to be looked at as an affectivecognitive variable associated with long-term language behavior rather than the temporal and unstable circumstantial L2 curiosity. Indeed, Mahmoodzadeh and Khajavy (2019) define language learning curiosity (LLC) as being, "....an inquiry-driven interest and desire to learn and use a foreign language" (p. 336). In their study, using descriptive statistical analysis, they surveyed 334 Iranian English language learners revealing that LLCs predict a more robust willingness to communicate than even enjoyment. Moreover, such curiosity is able to sustain students' WTC. This provides some evidence for the possibility that gritty L2 students are perpetually curious about the L2.

Emotions, in the form of anxiety and enjoyment, also seem to be related to L2 grit. Enjoyment was considered in a study conducted by Wei, Gao and Wang (2019). Using a shortened version of the Grit Scale questionnaire, they looked at 832 Chinese middle-school students to see if grit would affect their foreign language performance (FLP), foreign language enjoyment (FLE) and classroom environment (CE). Using age and gender as control variables, correlation and regression analysis of the relationship between grit and FLP, CE and FLE revealed that there were significant correlative effects between all of the factors. More precisely, "The results indicated that grit positively affected FLP. In addition, FLE mediated the relationship between grit and FLP, and CE moderated the relationship between grit and FLE, and between grit and FLP" (p. 1).

Changlek (2015) examined relationships between anxiety, motivation and grit as well as their robustness at being predictors of language learning success. His research investigated 180 L2 university students at a large Thai university. By employing a motivation questionnaire, a 
foreign language anxiety questionnaire, and a grit questionnaire, his findings showed motivation was correlated to both grit and anxiety. More specifically, it was found that among high achievers, motivation and grit were significantly and positively correlated, while an inverse relationship was found between the constructs of anxiety and grit. On the other hand, for low achievers, there was a significant positive correlation between anxiety and motivation. Interestingly, extrinsic motivation in the form of negative evaluations and test anxiety predicted low achievement while intrinsic motivation in the form of personal satisfaction with learning the L2 predicted high achievement (see also Changlek \& Palanukulwong, 2015; Sudina \& Plonsky, 2020).

Although, not looking specifically at grit per se, anxiety was also examined by Şimşek and Dörnyei (2017). The researchers looked at the anxiety levels of 74 Turkish English language learners to assess anxiety's affect on their own self image and consequently their motivation. In this qualitative study, where categories emerged (similar to the present study), the researchers found that students' 'anxious selves' manifest in three ways: safe players (those who simply try to manage L2 anxiety), quitters (those who try to escape from L2 anxiety) and fighters (those who actively combat their L2 fears and anxieties). Fighting behavior seems to be at least somewhat synonymous with grit-like behavior as can be seen from one participant's assessment of her own approach when dealing with anxiety, "What I am saying is I do not give up" (p. 62).

Boredom, or a lack thereof, may be another factor influencing the L2 behavior of gritty students. Although it is a complex concept, which can be tied to a L2 learner's disposition or weariness, boredom may be affected by a lack of enjoyment or becoming restless in the classroom (Dewaele \& MacIntyre, 2016; Kruk, 2015). We believe it is important, inasmuch as the length of time studying the L2 seems to be an important element associated with boredom and enjoyment. For example, in a study of 548 German learners of French, Beerman and Cronjäger, (2011) found that when learners held a positive view of French language instruction their perceptions were significantly and positively correlated with joy and negatively correlated with boredom. However, over the three year study period joy and boredom followed distinct trajectories - the longer the instruction, the less joy and more boredom learners experienced. Especially related to the issue of time, it may be the case that gritty learners have sufficient selfregulatory time sensitive strategies to help them overcome L2 boredom as Kormos and Csizér (2014, p. 295) hint at:

“...efficient management of time and boredom as well as proactivity in seeking out learning opportunities seem to be equally necessary to promote the autonomous use of traditional learning resources."

In addition, there might be a connection between extraversion and grit because of a fundamental belief that communication is at the heart of learning a L2. This rests on one of the key tenets of the Big Five Model (Dörnyei \& Ryan, 2015; Goldberg, 1981; 1992; 1993; McCrae \& Costa, $1989 ; 2003 ; 2008)$, namely the extraversion, introversion continuum. The model assumes that extraversion and introversion are personality traits. Extraverts tend to be highly sociable, gregarious, active, assertive, passionate and so are naturally loquacious as well and consequently, would be more likely to demonstrate a willingness to communicate (Dewaele \& Furnham, 2002) It may indeed be the case that gritty students display some of these attributes - especially regarding talkativeness and WTC. Research seems to be pointing in that direction. In what has become a foundational study on L2 grit, Teimouri, Plonsky and Tabandeh (2020) formulated a L2 grit survey to measure L2 learners' language behavior and their achievement. The research presented 191 EFL learners with a nine-item questionnaire developed from teachers' assessment of student grit as well as a various student-based factors including: (1) motivational measures, which encompassed intended effort, willingness to communicate (WTC), attention and mindset malleability, as well as (2) emotional measures, which included L2 anxiety and L2 joy; and lastly (3) L2 achievement measures, which were based upon students' grades in various language learning courses and their language proficiency. They found that emotional stability and extraversion were significant predictors of L2 grit but that a L2 learner's conscientiousness was not. Teachers' assessment was positively correlated to both students' general grit and L2 grit, which hints at important practices for L2 teachers. As for the motivational measures, intended effort, WTC, attention as well as a malleable mindset also correlated positively to both general and L2 grit. Positive correlations were found for the emotional 
construct L2 joy with the expected negative correlations for L2 anxiety. Of significant importance is that L2 emotional factors (i.e., intended effort, L2 WTC, attention and teacher perception) presented much stronger correlations than for general grit. Finally, concerning grit and L2 achievement, there was a moderate correlation between L2 achievement and grit. Beyond extraversion, these findings have broad implications for the learning of languages and for L2 teachers, and as such, the questionnaire represents a solid foundation for the expansion of L2 research on grit.

As for additional predictors of gritty students, we wanted to see if there were any past experiences and/or personal encounters which students could identify as being important factors to their becoming gritty L2 learners. Freiermuth and Ito (2020) examined the WTC of eight Japanese English language learners via face-to-face interviews. The participants who indicated a high WTC consistently had past experiences or personal encounters with other individuals, which almost certainly contributed to their higher WTC. Those learners with high WTC consistently had vivid images of happy events and positive encounters with individuals - L2 teachers and foreigners - which they believed to be of critical importance to their WTC. Why this is important for the present study is that many of those positive L2 experiences occurred many years prior to the interviews indicating that the experiences were not only momentarily motivating but had a long-term effect possibly contributing to making them gritty L2 learners as well. In addition, as was pointed out in many of the aforementioned studies, WTC seems to be a variable which has been consistently, positively correlated to L 2 grit. It may be the case that past positive experiences and personal encounters with others - as was the case in the Freiermuth and Ito study (2020) - may have a positive influence on L2 learners, either putting them or keeping them on the path to becoming gritty L2 learners.

We mentioned L2 vision at the start of the literature review. It is reasonable to think that L2 grittiness and L2 vision may go hand-in-hand inasmuch as L2 motivation can be recharged when learners focus their attention on longterm goals, which may reinforce their determination. Dörnyei's (2009) L2 Motivational Self System discusses vision in the form of what students' possible L2 selves of the future might look like. Consequently, vision can be a motivational force for a student to become the ideal L2 learner he or she imagines. The difference between the student's present L2 self and the future ideal L2 self represents the hurdle which must be overcome to achieve L2 success (see Dörnyei \& Kubanyiova, 2014; Markus \& Nurius, 1986). Becoming the desired L2 self may require students to give an extended effort over many years to arrive at their imagined ideal self; as such, we believe it is important to see if gritty students have a strong L2 vision that strengthens their resolve to accomplish their language learning objectives.

In addition, there are influential studies on grit that fall outside the L2 realm but which do pose challenges to grit research in general. Credé, Tynan and Harms (2016) and later Credé (2018) criticized the grit research to-date on measures of various types of validity and the attraction of combining perseverance and passion as the single construct of grit, essentially questioning whether or not grit is even a valid avenue of pursuit. In addition, even if grit can be considered a valid construct there are still questions about whether or not it is a good predictor of success. As such, they have called for more research and fundamentally better research. We believe that descriptive researchers should also heed this call.

Because much of the L2 grit research has relied on empirical research without much attention to descriptive analysis, we wanted to examine the depths of interview data using the tenets of Charmaz's (2006) Grounded Theory as it applied to the data of our participants. More specifically, we ask the following research question:

RQ: What notable factors are prevalent among and affect gritty EFL/ELF learners?

\section{METHOD}

As a first step, the researchers involved in this study - who are also L2 teachers in Taiwan, Malaysia, Thailand and Japan-administered the L2 grit survey, as developed by Teimouri, Plonsky and Tabandeh (2020), to their own university students. Following this, eight student were selected to participate in the personal interviews based upon their higher than average grit scores $(+4.0$ or higher mean scores) obtained from the questionnaire. All of the participants were female and aged between 20 and 25 years old. The following table provides relevant information 
Table 1. Participant Profiles

\begin{tabular}{lccccccc}
\hline Student & Age & First language & Country & Sex & EFL & ELF & Major \\
\hline Chirawan & 21 & Thai & Thailand & F & X & English \\
Malee & 22 & Thai & Thailand & F & X & & English \\
Dixia & 23 & Tamil & Malaysia & F & & X & English Language and Communication \\
Mysha & 25 & Tamil & Malaysia & F & & X & English Language and Communication \\
Emma & 20 & Chinese & Taiwan & F & $X$ & & English Communication \\
Olive & 24 & Chinese & Taiwan & F & $X$ & TESL \\
Mariko & 21 & Japanese & Japan & F & $X$ & International Business \\
Remi & 21 & Japanese & Japan & F & $X$ & English Communication \\
\hline
\end{tabular}

regarding those who agreed to participate in the case study. All of the students' names used here are pseudonyms of their actual names.

After student grit scores were determined, permissions were secured for all of the participants. The interview questionnaire developed and used was an expansion of Teimouri, Plonsky and Tabandeh's (2020) shortened L2 grit questionnaire in combination with the original questionnaire developed by Freiermuth and Ito (2020) which considered students' previous experiences. The questionnaire was sent to the selected participants in advance so they would have time to think about their answers prior to the actual interview. This was a reasoned decision aimed at getting the most complete and accurate responses possible.

The L2 learners were then interviewed in semistructured fashion with the idea that students could talk as much as they wanted to on any topic. Follow-up questions were employed for clarity or expansion. Due to this approach, the shortest interview took longer than 25 minutes to complete. This kind of open-ended interviewing style has been promoted by Charmaz (2006) as a means to generate robust qualitative data, and as such, we followed the tenets of her approach here. All of the interviews were done remotely using telecollaborative video in one-on-one fashion. The interviewer for each student also worked within the country where the student lived and attended university. The interviews were conducted in English and participants overwhelmingly responded in English.
Following each interview, the video files were saved and the transcripts were then generated using NVivo software, which were then saved as narrative text in individual Word files; time-consuming corrections and additions were then made for each transcript. Here we used a very straightforward transcript style as our focus was primarily on the content produced. The transcripts were then compiled and saved in MS Notepad and then copied and pasted into MS Word. Once the transcripts were saved as one large document, they were examined for content-based threads that seemed to have some relationship to L2 learner grit. Using Grounded Theory (Charmaz, 2006) as the base for the emergent categories, the document was tagged with color highlighting in accordance to the categories that had emerged. Specific categories were identified and then either accepted as being central (at least five participants pointing to the weightiness of the issue) or rejected as being idiosyncratic. The factors can be tied to the previously discussed literature either directly or relationally. The categories were confirmed by three researchers. We then looked for similarities and differences among the participants. The following categories were identified by the learners as being significant to them:

- Perseverance

- Curiosity

- Enjoyment

- Anxiety

- Boredom

- Extraversion versus introversion (WTC focus) 
- Vision of English (forward thinking objectives)

- Predictors of present L2 behavior

- Events

- Personal encounters

- Personal encounters with L2 teachers

We will discuss these factors based upon the students' own perspectives as expressed in the interview data. Because the learners were encouraged to answer in narrative-style, the data pool became quite large (close to 35,000 words in total), so we can only mention snippets here with the overall aim of providing the learners' positions on each of these categories - if they did indeed take a position.
Prior to presenting the findings, we considered factors that were discussed in the literature review that focused on grit and other factors that may be related to grit. As such, we make certain assumptions based upon their findingsnamely that L2 grit is associated with certain psychological concepts. We attempt here to discover if such factors seem important to the participants and in what ways they may be manifest in the lives of the students. This is raised here for two reasons. First, this carries an element of risk, inasmuch as this line of research is still in its infancy, especially in L2 research, and second, when looking at purely descriptive data, there tends to be a frequent overlapping of concepts.

From the descriptive comments made by the participants, we colligated the themes that were intricately connected to our understanding of their grittiness. Table 2 is a compilation of our findings.

\section{RESULTS \& DISCUSSION}

Table 2. Characteristics of High-Grit English Language Learners

\begin{tabular}{|c|c|c|c|c|c|c|c|c|c|c|c|}
\hline $\begin{array}{l}+\frac{7}{\bar{D}} \\
\frac{0}{0} \\
\frac{D}{D}\end{array}$ & 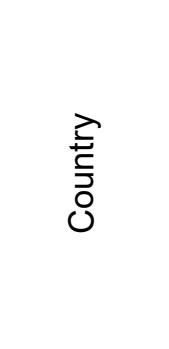 & 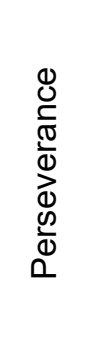 & 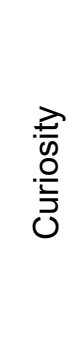 & 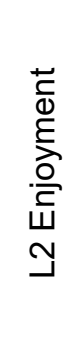 & $\begin{array}{l}\frac{\vec{d}}{.0} \\
\frac{0}{x} \\
\frac{1}{4} \\
y\end{array}$ & 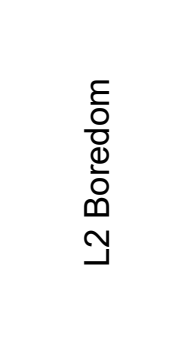 & 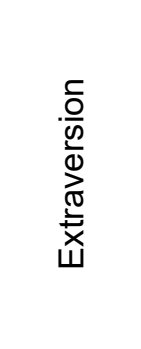 & 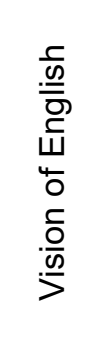 & 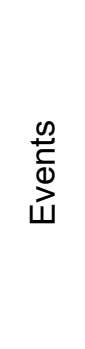 & 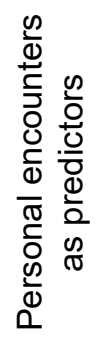 & 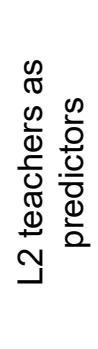 \\
\hline Chirawan & Thailand & Yes & Yes & Yes & No & Sometimes & No/Yes & High & Yes & Yes & Yes \\
\hline Malee & Thailand & Yes & Yes & Yes & No & Rarely & Yes & High & Yes & No & No \\
\hline Dixia & Malaysia & Yes & Yes & Yes & No & Never & Yes & High & Yes & No & No \\
\hline Mysha & Malaysia & Yes & Yes & Yes & - & Sometimes & No/Yes & High & Yes & Yes & Yes \\
\hline Emma & Taiwan & Yes & Yes & Yes & - & Never & Yes & High & Yes & - & No \\
\hline Olive & Taiwan & Yes & Yes & Yes & No & Rarely & Yes & High & Yes & Yes & Yes \\
\hline Mariko & Japan & Yes & Yes & Yes & No & Never & Yes & High & - & Yes & Yes \\
\hline Remi & Japan & Yes & Yes & Yes & No & Never & Yes & High & Yes & Yes & Yes \\
\hline
\end{tabular}

Most participants gave relevant comments for each theme; however, due to space limitations, additional descriptions for each category can be found in the Appendix following the References.

\section{Perseverance}

Although perseverance is a defining feature of a learner's grit, we felt it important to establish that besides the grit survey, students would self-identify their perseverance. We looked for themes such as not quitting or continuing even 
when situations became difficult. All of the learners expressed their motivation in terms of sustained effort. Here are some comments provided by two of the L2 learners.

Chirawan: I try hard. I study every night, every single night and every time I have free time. And also I study more. And almost every time like I spend my time with English. So it was hard. But others see that I study a lot. But for me, I didn't see it like it was like too much. I just get used to it.

Remi: Uhh the...I wanted to give up first. But I went to language school for like a decade and my mom at first my mom let me go there and I didn't know what English was like. And then I asked my mom, like oh. I don't I don't want to keep going there. And she said like Oh, yeah. If you want just just quit it. And I was like, oh, that's so like, unexpected answer. And I and also at the same time, I met the band and I feel like, oh, that's so cool. So like those opportunity or chances that I had at the same time made me feel like, oh, I want to study more...I just expected my mom would say, like just keep doing like, don't quit that school, but she said like just quit it if you want and I was like, why? You know like I kind of felt like, oh, she says, so I want to keep going. You know I don't know how to explain that feeling, but I thought, I thought so. So I just didn't give up.

For all of these learners, English represented an integral part of the very fabric of their lives. To a student, they talked about using English regularly, and they all mentioned experiences of overcoming a variety of L 2 hurdles. They all seemed to possess a kind of fighting spirit when facing L2 problems and setbacks (Şimşek \& Dörnyei, 2017). They were all long-term L2 achievers, which hints at their resiliency as language learners (they all agreed to be interviewed in English, so their achievements were already tacitly recognized). Clearly, each of these students approached the L2 with a steely determination which they still maintained at the time of the interviews (Teimouri, Plonsky \& Tabandeh, 2020).

\section{Curiosity}

Interestingly, students' indicated a sustainable drive to satisfy their persistent L2 curiosity - a concept associated with positive psychology. We looked for simple ideas related to a drive to find things out or to explore. Here are some examples of their curiosity about English:

Malee: And you might also find this weird, but I sometimes talk alone. For example, when I was in the bathroom, I describe what are in my bathroom. So if there are any words or if there any sentence that I don't know uhm, if there any structures that I couldn't think of, then I would try to find it right after I finish my peeing in the bathroom.

Dixia: .... if I watch a movie or a cartoon, if I find a new word like a new vocab, I will look for the meaning in dictionary. So I used to have like a small mini dictionary for myself. Like so whenever I watch a movie or I read a story book, if I find any new words that I don't know the meaning , I will write it down and I'll find for the meaning, and then I will keep using it so that I won't forget it. And how I didn't give up is ah because I know how important it was, because having a good command of English can actually help us to have more opportunities in life...

From these comments, we suggest that students who indicate robust L2 grit scores are also likely to have language learning curiosity, which keeps them moving in the 'right' direction - tying the learners to their L2 friends and teachers in a 'healthy manner' (Mahmoodzadeh \& Khajavy, 2019).

\section{Enjoyment}

As Teimouri, Plonsky and Tabandeh (2020) have suggested, L2 enjoyment is something that correlates well with L2 grit, and in tandem, the pair may be seen as being associated with positive psychology. Although it is true that enjoyment may be absent from L2 learning that is driven by extrinsic motivation or an 'ought-to-self,' the learners' comments in this case study were tied more often to intrinsic motivating factors (Ryan \& Deci, 2000; Dörnyei, 2009; Dörnyei \& Ryan, 2015; Rigby, et al. 1992). We looked for words such 
as joy, love of the L2, enjoyment or fun as being relevant to joyful L2 learners. Here are a couple of comments:

Emma: And I think this can explain why I said ah I have loved English for probably five years. So ah, ah I watched ah a TV series called The Hollow Crown ah when I was 16, in high school. And the series was based on William Shakespeare's history dramas, history plays, ah Richard II, Henry IV, and Henry V. And ah it's...like...I was really fascinated by Shakespeare's words. And it's like the first time that I felt that language is beautiful, like English is very beautiful.

Mariko: And I I am so excited. I am so interested in staying overseas. And I thought... and I do love America, so I like I've wanted to live in America......Uhm actually speaking English looks so, like speaking English perfectly, fluently looks so cool. (laugh) And, actually, English is global language, right? So if I can, I can go everywhere. I can talk to every... everybody.

It could almost be said of these language learners that they display a kind of giddiness about their L2. They cannot imagine their lives without English playing a significant and positive role, or to quote Olive from Taiwan, "...English have been my good friend since I was a child."

\section{Anxiety}

As anxiety was negatively correlated to grit (Teimouri, Plonsky \& Tabandeh, 2020), the high grit score learners in this study tended to talk about confidence or not being afraid. Here are some comments that reflect these notions:

Dixia: Different people learn English different way. So you shouldn't compare yourself with other people. And also, when you learn English or when you speak English, you tend to make mistakes. So you shouldn't take the mistake personally or seriously. So mistakes only have all the powers that you allow them to have such power. So the goal of ah learning English is to communicate. The fact that it is that many mistakes actually don't damage the communication. So you need to...so these are the things that will motivate you.
Olive: Uhm, to learn English or some other foreign languages, you shouldn't be afraid to make mistakes. People can only correct your mistakes when they hear you make them. Nobody can prevent from making any other grammar errors when learning a language, even tongue language will be involved. Trying to be confident when you speak English... I tried to improve my English weaknesses by cultivating the courage to speak. Catch every chance to practice English, although sometimes it looks like a fool when speaking. When I don't know how to conjugate... conjugate... conjugate a verb correctly, I would say it anyway and find the correct answer after that. In this way, I could recognize and seize my own mistakes.

Although these students talked about their confidence and recommended that their peers not be fearful when learning languages, it is also true that many of them had to 'overcome' their initial fears and lack of confidence to become proficient users of the language. The ability to move beyond fearfulness was characteristic of all of these L2 learners - not that they had completely rid themselves of it but that it was no longer a debilitating emotional factor that kept them from communicating. A few of them mentioned it directly.

Chirawan: ...I didn't have the confidence to speak out like I kinda take it too seriously. Like in just for the test and for in class. Yes. But after I went abroad, I see that they didn't even care how you pronounce it correctly, or the grammar that the native doesn't even, like, speak correctly, grammatically correct. Yeah. So it made me more con ... be more confidence to speak out.

Mariko: Uhm because everybody like actually, even me, even I tried to speak English, tried to speak English perfect, perfectly. So like we think we don't have enough English skill so we cannot talk like we cannot talk. We cannot tell our mind or what we thinks like truly and perfectly. So we feel negative; we feel afraid to speak English, to use English uhh, because they don't want to try. So they fear. If we feel fear here, fear to use English, we don't try. And then that then we then we kind of, in a sense, give up, right? 
As a broader concept, fear of using the L2 seemed to be the primary source of anxiety. Many of these L2 learners experienced it, but they overcame much of their fear through language acquisition and practice. Our descriptive results align well with the conclusions made by Teimouri, Plonsky and Tabandeh (2020) who found that gritty students tend to have a more malleable mindset, which can be tied to their achievements and their perseverance in learning the language - both of which the learners in this study have indicated through their test scores and comments (see also Khajavy, MacIntyre \& Hariri, 2020). One additional note concerning anxiety is the element of time in combination with effort. Anxiety seemed to wane as students became progressively more capable in the L2 and in the process weakened its debilitating effects (Kormos \& Csizér, 2014).

\section{Boredom}

Another factor we considered was boredom because of our own experiences teaching L2 learners and because of the effect time has on boredom (Beerman \& Cronjäger, 2011). We looked for discourse pointing to a lack of fun, being tired or simply being bored. Being excluded from this category would be indicated by a learner talking about often becoming bored or frequently becoming bored, which no student mentioned. Some students alluded to boredom or commented directly on the topic:

Dixia: I feel that English is a never boring subject. It's not a boring subject at all, at all. Learning English is not boring at all because it's it's different from other subjects like history, math, di... It's all different, you know? So English is a very fun, interesting subject. There are many ways to learn English. There are many fun ways to learn English. Not only by reading, going to school, going for English lessons. No... Even my ahh telling my personal experience, I didn't go for any special English class or English fusion. I learn it by watching movies, watching cartoons. So it's like a fun way to learn English. So it's never boring to learn English actually. But there are many fine ways to achieve that English.

Remi: (Does English ever get boring?) No, no, no.
Interestingly, half of the gritty users mentioned never getting bored while learning English and the other half rarely or sometimes becoming bored. Moreover, L2 boredom was never mentioned in the context of using it to communicate. It was generally associated with completing assignments or listening to L2 teachers in class - influences completely beyond the learners' control (Nakamura, Darasawang \& Reinders, 2021). In other words, gritty L2 learners seem to have the capacity or self-regulatory strategies to overcome boredom or perhaps look beyond what some learners might consider the drudgery of learning a L2. We believe that Kormos and Csizér, (2014) are pointing in the direction of gritty learners when they say, "... acquiring an $\mathrm{L} 2$ requires memorization and occasionally monotonous practice. Hence, it is understandable that learners who are willing to invest energy into language learning will have more efficient strategies to overcome boredom than those who are less prepared to make substantial learning effort" (p. 292).

\section{Extraversion versus Introversion}

There has been some controversy over whether extraversion or introversion is the favored trait for gritty students (see Dewaele \& Furnham, 2002 for an extensive discussion on L2 extraversion). We looked for comments about conversing with others in the L2 or simply using the L2 to communicate or even being willing to use the L2. Our research clearly indicates a strong sense of extraversion based upon their comments and their general demeanor during the interviews.

Olive: I uh now I have less chances to talk with a native-speaker of English because uhm of the COVID-19. It is really a pity. I need to say because uh when I walking... when I when I walk down the street, I am very often to be asked a how to go to where. Yeah. They'll ask me a question, 'How can I go to Taipei main station or how can I go to [unintelligible]?' Yeah, so uh I always have a lot of chance to ah practice English.

Remi: (When asked about helping an unknown foreigner who is struggling with the local language) Yes, I would. Because mmm that's that's kind of my personality. But also a lot of people helped me in 
the U.S. and yeah, most people I mean, most people are...most people that helped me were my first time to that's broken English. But yeah. I've never talked with them, but they were like, oh, are you okay? Or do you need any help? And even just like on the campus. I had a balloon for 'Happy Birthday.' But that was not for my birthday, but my friends have hold that. And they asked me like, oh, do you want to hold it? And I was like, 'Yeah, of course.' And they let me hold them. And then, like so many people that I don't know, I didn't know. Just like told me, like, 'happy birthday' or 'have a good day.' And that really made me happy. So like those helping. I don't know what's it's called. But in Japan, we don't of course. But I really want to do those stuff even in Japan.

Direct communication was important for all of the interviewees, and although two students claimed introversion (Chirawan and Mysha), they also greatly valued face-to-face communication using the L2 (Dewaele $\&$ Furnham, 2002). Perhaps some of these students were introverted at some point in their L2 development and it may have been the reason two of them still claimed introversion. In addition, it is true that introverts may be willing to converse when they find themselves in a situation where they feel comfortable. Nevertheless, each of the students in this study claimed that they would happily go out of their way to help foreign strangers who were struggling to communicate when trying to talk to a local cashier who could not understand English well — a situation that would put them in a potentially very uncomfortable position. Here is what Chirawan and Mysha (the two introverts) actually said about being introverts.

Chirawan: I always help people (using the L2). Like even strangers, I know because I want to use my knowledge to help others.

Mysha: I was a very introverted person in high school and I was from a full girls school. So ah even though we...I won a lot of public speaking contests in school when I went to ah as a representative from school to a wider range of audience, where there where there were boys and everything, I got very nervous, but I actually got ah how to say got above the situation and actually used my English and were able to actually win that competition. So I felt very happy because uhm with my language skills, I was able to be above my introvertedness and be above my less self self-confidence and actually win. Even though like I was not very confident talking to boys being from all girls school, ah I was very nervous. But yeah, I actually got above the situation and I actually won the competition.

It appears that Mysha may have recognized that she was becoming more of an extravert with the successes she was having while using the L2, and if we can consider Chirawan's statement at face value, she certainly seems to be extraverted in accordance with her claims that she would use the L2 in any situation if she could help out with her L2 abilities. This implies that they may also be more willing to communicate in the L2 in the cases they believe their L2 will help them to resolve a troubled situation even when it means risking a potentially uncomfortable encounter in the L2 (MacIntyre et al., 1998). Thus, we concur with Dewaele and Furnham (2000), who suggest that, extraverts tend to be more fluent in the L2 than introverts and they are able to maintain that fluency over time, such as communicating in English during an extended interview. On the whole, extraversion as expressed by these students was demonstrated by their WTC in the L2 - even in situations that fall outside of their normal routines and even with complete strangers, thus stressing the importance of oral communication with others (Dewaele \& Furnham, 2000; 2002; MacIntyre, et al. 1998). Students had little trouble maintaining a very long interview using their L2 extensively. To sum up, we once again concur with the findings of Teimouri, Plonsky and Tabandeh (2020), who found that gritty students also tended to be extraverted students.

\section{Vision of English}

We wanted to examine how gritty students see themselves using English in the future. As Table 2 indicates, all of the students indicated their L2 vision. We looked for comments about dreams, future uses and imagination. Here are a couple of their comments:

Mysha: Oh, ah I would definitely love to publish my own novel. That has been the dream for a very, very long time for me. Ah, writing and publishing my own novel or being known for my writings or being 
known for my journaling is one of the things that it's like the major, major goal in my life. And I would also like to teach to young children that in a place that do...they do not have access to learn English. Growing up in the big city with all the access I have with the money that I can buy, book, storybooks, all the book I want. It was very easy for me to actually learn English and actually adopt English in my lifestyle. But there are children in rural areas that can't speak English. Because. Because they do not have ah facilities like, for example, ah the new teacher the Samuel Azziah teacher, whose gaining a lot of ah perspective getting a lot of respect, and he was nominated to be one of the best teachers in the world, uses his English in a good way, it's one of the things that I wish I can do with my English, where I can go up ah to rural areas and actually teach them English. Yeah, that will be one of my dreams....I never thought of it of a skill because I thought, oh, everyone has it. But when I met new people and I'm talking to people, then I realized, oh, is actually a skill. It is actually ah it's like how to say it a talent I would say or like a software like ah soft skill. I do want to use that soft skill. I don't want it to go to waste.

Emma: Uhm, I think because it's, it's very useful. It's very useful, and I will say it's like "practical" because ah we use it every day, or for me, I have to read English every day. And it's an international language. So ah if you want to communicate ah with people from other countries, then it would be English......I imagine myself, well, only talking in English. Not singing, not singing, just talking. And with native speakers ah in both workplace and in private time. Yes and ah those people could be colleagues from works or just friends in private.

Gritty students in this study could not envision a scenario where English did not play a prominent role in their lives, and all but one (who ironically is teaching English already), dream of using English on the job (Kormos \& Csizér, 2014; Yashima, 2009). They all had a clear vision of who they were becoming and the importance of English in getting them to that place (Dörnyei, 2009). As Dörnyei and Kubanyiova (2014) stress, L2 learners with clear, strong and active L2 visions coupled with realistic objectives are able to sustain their motivation towards transformative successes. As for the gritty learners in the present study, their second language had already become an integral part of what they see as a permanent identity.

In addition, from the comments related to employment, it appears that certain extrinsic motivational factors are important to these gritty language learners as well; however, we surmise here that the intrinsic joy of using English regularly is the underlying foundation for the extrinsic aims of getting a job that requires English use. This type of extrinsic regulation lacks external coercion because the learners "... would not behave simply because they feel they should, but rather because of the personal importance of the behavior. This results when they have identified with the underlying value of the activity and accepted its regulation as their own. It occurs as they begin to incorporate the value and regulation into their sense of self" (Rigby et al., 1992, p. 170).

\section{Predictors: Events, Personal Encounters and L2 Teachers}

\section{Events}

This final section's aim was to see if there were any significant events, habits or people in the lives of these language learners. Could they pinpoint habits or events, which they felt were important or were there any personal encounters they viewed as being vital sparks to their L2 grit development? Here we look at two events that seemed to have had a significant impact on Malee and Dixia.

Malee: Uhm, I guess, yes, when I passed the interview for the AFS student intercultural exchange program, uhm I was chosen to be an exchange student in Germany and I was like 15 or 16 at the time and really, really wanted to participate the program. But my parents said that I was too young and they didn't. They didn't agree to let their only daughter leave in abroad for a ... at a very young age. And I think that is when my love of English got fueled, because after that I thought I have to work even harder to prepare myself to be as qualified as I could for the opportunities to come in the future. (being chosen as an exchange student) 
Dixia: ...I was learning English since kindergarten, but I started to love English when I was in primary and secondary school because we always have these clubs like English clubs. So I was always in a part of the English clubs. Like until now I am a part of English clubs, ah I find it very interesting, the events that we had, we organized some events like the English Carnival. So those events actually made me love English language. (participation in English clubs and carnivals)

\section{Personal Encounters and L2 Teachers as Predictors}

Of course, we also asked gritty students about people who might have influenced them in the past. Some of them pointed out teachers and others did not. Here are two snippets from the interview data.

Mysha: Ah, first I think it's my mom with the examples given before. Second, I think ah it's one of my friends in primary school, her name is FangFang (pseudonym). She doesn't really know how to speak English because she grew up in a household that only speaks Mandarin. So ah she will always ask me that my English is very good. I think when I was like eight, nine years old, so she would always encourage me. 'Oh, my God, your English is so good; your English is so good.' So I actually had like a self boost confident and actually kept on improving and kept on talking English with their parents. I think that made me love that language so much because I was not good at math. I was not good at that subject. I was I was happy that I was very good at English. There is something that I'm actually very good at. So maybe that fueled me to go for the learning English... Ah, if...the first thing that I think when I when the word English teacher comes up about is my standard six English teacher, Chenchi Chang (pseudonym). She always encouraged me ah to read more novels and she would personally suggest me this because I would always...In school, I was always ah how to say this. I always daydream because ah I like to create stories in my head and then just imagine stuff that happens. And all the other teachers were just complaining to my ah mother that I always daydream and all those things. But Chenchi she never said that. She's always said that whenever you feel ah you are daydreaming or you're just wandering off to some some somewhere, you just write it you, you just pen it down. So that's why I started journaling... (mother, her childhood friend and her Standard 6 English teacher)

Mariko: Actually, my friend in university. Yeah, there's...they studied English so hard. So I always think, uhh intensive. Ah, yes, actually my teacher-junior high school teacher...She, she worked at, she had worked at the Colombia. I think Colombia. Yeah, Columbia and she told us like she told us like her lifestyle in Colombia. Actually, Colombia is Spanish country. Spanish country, but like she used English......actually, um, I like I like talking to Eng...native teacher in university in [university name] also you so it keeps me studying English. (friends, junior high school teacher and her present teachers including the interviewer)

What is of importance from these comments is that although events and L2 teachers play a role in these students' L2 grit development, such things may simply light a fuse or they might not even be required. These students seem exceedingly focused and are autonomous L2 learners. Certainly, they are taking university level classes that have a L2 focus, but they are comfortable using the L2 and can visualize their ideal identities as future English users.

Undoubtedly, there is a temporal element involved here too. They may have been dependent L2 learners at one point in time - needing to be made aware of the L2, involved with the L2 and requiring L2 intervention from others. It may be the case that these L2 students' gritty nature has carried them to a point where they have become creators of their own L2 opportunities (they all allege looking for opportunities to use the L2) while many of them may be either on the verge of being in the transcendent stage along the L2 continuum or fully immersed in it, to the point that they may be capable of teaching others about the L2 or are completely at ease investigating intricacies of the L2 completely on their own. Most of these students have mentioned fascination with various linguistic elements of English (Nunan, 2004). Nevertheless, this may be the case for only advanced gritty L2 learners or that this was 
idiosyncratic to these learners; this supposition certainly warrants further investigation to be supported and is only mentioned here as a possibility.

\section{CONCLUSION}

The primary aim of this study was to dig a bit deeper into the background of students who recorded high grit scores. For the most part, we find our research to be in harmony with the studies we have cited throughout the paper (Changlek \& Palanukulwong, 2015; Khajavy, MacIntyre \& Hariri, 2020; Mahmoodzadeh \& Khajavy, 2019, Sudina \& Plonsky, 2020; Plonsky \& Tabandeh, 2020; Wei, Gao \& Wang, 2019) but we will briefly mention our conclusions in more detail here.

First and perhaps foremost, students' robust grit scores coincide well with their L2 self-images built upon such aspects as their determination, their vision, their curiosity and simply because they all seem to enjoy using English. For the most part, these gritty L2 learners have developed confidence in their own abilities to use the L2 and this further strengthens their resolve. In many cases, we surmise that they are already experiencing the fruits of becoming their ideal selves (Dörnyei, 2009; Mahmoodzadeh \& Khajavy, 2019; Teimouri, Plonsky \& Tabandeh, 2020). In addition, they seem to be incessantly curious by various aspects of learning their L2 including linguistic elements, and they express a deep joy in learning it.

If we think about L2 learning on a continuum as suggested by Nunan (2004), we can see that they are beyond the stage where they fear using the L2. Being able to communicate with others directly is critically important to each participant, so negative elements such as the fear of making mistakes and L2 learning anxieties are viewed as part of the learning process, and as such have been and continue to be overcome. They have the confidence to seek out opportunities to use the L2-especially communicatively. They either claim extraversion or at the very least are willing to communicate with others in the L2 if they believe using their L2 might help to resolve a situation where the L2 could be of service to others. In addition, although some of them expressed sentiments of boredom while 'studying the L2,' not one student mentioned being bored using it to communicate with others. In other words, they view boredom as a situational phenomenon that will pass (Kormos \& Csizér, 2014). Our interview data show that gritty students view communication as being paramount and a measure of their own success.

Finally, we would like to mention influences on the learners. Most gritty L2 learners could point to certain events or habits that were important to them in their L2 linguistic development. Such things help them to mark time as to when English became a part of their lives. Not all of them could name a person in their past (friend, family member or L2 teacher) who they felt was particularly important to their grit development. Perhaps these students thrive on their own resiliency in learning the L2. For others, though, much stronger images of personal intervention were mentioned as playing a significant role in the L2 development (Freiermuth \& Ito, 2020). It would be very interesting to track L2 student grit over an extended period of time - preferably starting when a learner was young and following it up on a year-by-year basis.

In summary, the picture of a gritty L2 learner emerging from the excerpts presented here looks something like this: They are resilient and determined L2 learners who seem to have an unquenchable curiosity about the L2. They do not let hurdles or setbacks derail them. In fact, as they also tend to be fighters, they do not let anxieties derail them either. They are rarely bored when learning the L2 and in cases where they are bored it is circumstantial - they are never bored when communicating face-to-face in the L2. Even though they tend to be advanced learners, they continue to have strong L2 visions in the form of their hopes and dreams. Their pasts do play a role in their grit development. There are events and personal encounters representing milestones on their language learning journey that gritty L2 learners can point to as being very important to them.

This study has some limitations that must be mentioned. Descriptive case studies by nature are small. Here we looked at only eight students. Nevertheless, the volume of descriptive data presented here (not to mention the excluded data), lends credibility to the findings. Second, this study has an Asian bent and so findings cannot be generalized to other contexts. Third, we looked only at female participants. This was our goal at the outset, but this also means that interviewing male participants may have revealed some differences. In addition, all of these students were already proficient users of the L2. It may be the case that some 
beginners are indeed gritty L2 learners; however, in all honesty, such students were difficult to locate given the apparent need to develop grit over time. It may be the case that grit tends to strengthen as language proficiency increases, but this will need to be examined in more detail in future research.

As a final note, we consider grit to be an integral part of L2 development for high proficiency users. All of the students in this study were confident L2 users, so the interviews in English were easily managed by them. We believe this is not simply by chance. One element that was repeatedly mentioned by students was the importance of interactive communication. Hence, opportunities for students to use the L2 should be encouraged by L2 teachers and consequently, should be valued and incorporated into classrooms and curricula with the hope of aiding students in their L2 grit development - that is the nitty-gritty of L2 grit.

\section{Author Contributions}

MRF designed the original study and collated the findings. All of the researchers (MRF, CP, LR, \& HH) distributed the Grit Survey to their students and then conducted open-ended interviews with students that scored at least 4.0 on the Grit Survey. In addition, $\mathrm{HH}$ used NVivo software to convert the video data to text. MRF then edited the final texts by reviewing the actual video data to ensure the accuracy of the transcribed texts. All authors read and approved the final manuscript.

\section{Ethics Approval \& Consent to Participate}

All of the students in this study agreed to participate in the study, and this study was carried out in accordance with the ethics rules for each university involved.

\section{Funding}

The authors received no funding or financial support for this work.

\section{Disclosure Statement}

No conflict of interest was reported by the authors.

\section{REFERENCES}

Beerman, C., \& Cronjäger, H. (2011). Die Rolle der Fachwerteschätzung für Freude, Langeweile und Angst im Fach Französisch: Eine mehrebenenanalytische Längsschnittstudie über die Sekundarstufe I unter Verwendung von Piecewise Growth Modellen. Zeitschrift für Interkulturellen Fremdsprachenunterricht, 16, 1834.

Changlek, A. (2015). Motivation, anxiety and grit as predictors of achievement in learning English as a foreign language. [unpublished M.A. thesis] Prince of Songkhla University.

Changlek, A., \& Palanukulwong, T. (2015). Motivation and grit: Predictors of language learning achievement. Veridian E-Journal, 8, 23-38.
Charmaz, K. (2006). Constructing grounded theory: A practical guide through quantitative analysis. SAGE.

Credé, M. (2018). What shall we do about grit? A critical review of what we know and what we don't know. Educational Researcher, 47, 606-611. https://doi.org/10.3102/0013189X18801322

Credé, M., Tynan, M., \& Harms, P. (2016). Much ado about grit: A meta-analytic synthesis of the grit literature. Journal of Personality and Social Psychology, 113, 492-511. https://doi.org/10.1037/pspp0000102

Costa, P., \& McCrae, R. (2008). The revised NEO personality inventory. In G. Boyle, G. Matthews, \& D. Saklofske (Eds.), The SAGE handbook of personality and assessment: Volume 2 Personality and measurement testing (pp. 179-199). SAGE. 
Dewaele, J.-M. (2012). Personality: Personality traits as independent and dependent variables. In S. Mercer, S. Ryan, \& M. Williams (Eds.), Psychology for language learning: Insights from research, theory and practice (pp. 42-57). Palgrave Macmillan.

Dewaele, J.-M. (2014). It takes two to tango: The dynamic interaction of emotional and psychological aspects in foreign language learning. ETAS Journal: The Magazine for English Professionals, 31, 51-53.

Dewaele, J.-M., \& Furnham, A. (2000). Personality and speech production: A pilot study of second language learners. Personality and Individual Differences, 28, 355-365. https://doi.org/10.1016/S0191-8869(99)00106-3

Dewaele, J.-M., \& Furnham, A. (2002). Extraversion: The unloved variable in applied linguistics research. Language Learning, 49, 509-544. https://doi.org/10.1111/0023-8333.00098

Dewaele, J.-M., \& MacIntyre, P. D. (2016). Foreign language enjoyment and anxiety: The right and left feet of the language learner. In T. Gregersen, P.D. MacIntyre, \& S. Mercer (Eds.), Positive psychology in SLA (pp. 215-236). Multilingual Matters.

Dörnyei, Z. (2009). The L2 motivational self system. In Z. Dörnyei \& E. Ushioda (Eds.), Motivation, language identity and the L2 self (pp. 9-42). Multilingual Matters.

Dörnyei, Z., \& Kubanyiova, M. (2014). Motivating learners, motivating teachers: Building vision in the language classroom. Cambridge University Press.

Dörnyei, Z., \& Ryan, S. (2015). The psychology of the language learner revisited. Routledge.

Dörnyei, Z., \& Skehan, P. (2003). Individual differences in second language learning. In C. Doughty \& M. Long (Eds.), The handbook of second language acquisition (pp. 589-630). Blackwell.

Duckworth, A. (2013). Grit: The power of passion and perseverance. Scribner.
Duckworth, A., Peterson, C., Matthews, M., \& Kelly, D. (2007). Grit: Perseverance and passion for longterm goals. Journal of Personality and Social Psychology, 92 1087-1101. https://doi.org/10.1037/0022-3514.92.6.1087

Ericsson, K., \& Charness, N. (1994). Expert performance: Its structure and acquisition. American Psychologist, 49, 725-747. https://doi.org/10.1037/0003-066X.49.8.725

Freiermuth, M. (2020). Introduction and overview: The inescapable confluence of technology, psychology, second language learners and users. In M. Freiermuth \& N. Zarrinabadi (Eds.), Technology and the psychology of second language learners and users (pp. 3-32). Palgrave Macmillan.

Freiermuth, M., \& Ito, M. (2020). Seeking the source: The effect of personality and previous experiences on university students' L2 willingness to communicate. Learning and Motivation, 71, 1-13. https://doi.org/10.1016/j.1mot.2020.101640

Goldberg, L. (1981). Language and individual difference. The search for universals in personality lexicons. In L. Wheeler (Ed.), Review of personality and social psychology (Vol. 2, pp. 141-165). SAGE.

Goldberg, L. (1992). The development of markers for the Big-Five factor structure. Psychological Assessment, 4, 26-42. https://doi.org/10.1037/1040-3590.4.1.26

Goldberg, L. (1993). The structure of phenotype personality traits. American Psychologist, 48, 26 34. https://doi.org/10.1037/0003-066X.48.1.26

Howe, M. J. A. (1999). Genius explained. Cambridge University Press.

Khajavy, G., MacIntyre, P., \& Hariri, J. (2021). A closer look at grit and language mindset as predictors of foreign language achievement. Studies in Second Language Acquisition, 43(2), 379-402. https://doi.org/10.1017/S0272263120000480

Kormos, J., \& Csizér, K. (2014). The interaction of motivation, self-regulatory strategies, and autonomous learning behavior in different learner 
groups. TESOL Quarterly, 48, 275-299.

https://doi.org/10.1002/tesq.129

Kruk, M. (2015). Variations in motivation, anxiety and boredom in learning English in Second Life. The Eurocall Review, 24, 25-39.

https://doi.org/10.4995/eurocall.2016.5693

MacIntyre, P. D., Clément, R., Dörnyei, Z., \& Noels, K. (1998). Conceptualizing willingness to communicate in a L2: A situated model of confidence and affiliation. The Modern Language Journal, 82, 545-562.

https://doi.org/10.1111/j.15404781.1998.tb05543.x

Mahmoodzadeh, M., \& Khajavy, G. (2019). Towards conceptualizing language learning curiosity in SLA: An empirical study. Journal of Psycholinguistics, 48, 331-351. https://doi.org/10.1007/s10936-018-9606-3

Markus, H., \& Nurius, P. (1986). Possible selves. American Psychologist, 41, 954-969. https://doi.org/10.1037/0003-066X.41.9.954

McCrae, R., \& Costa, P. (1989). Rotation to maximize the construct validity of factors in NEO personality inventory. Multivariate Behavioral Research, 24, 107-124.

https://doi.org/10.1207/s15327906mbr2401_7

McCrae, R., \& Costa, P. (2005). Personality in adulthood: A five-factor theory perspective. Guilford Press.

McCrae, R., \& Costa, P. (2008). The five-factor theory of personality. In O. John, R. Robins, \& L. Pervin (Eds.), Handbook of personality: Theory and research (pp. 159-181). Guilford Press.

Nakamura, S., Darasawang, P., \& Reinders, H. (2021). The antecedents of boredom in L2 classroom learning. System, 98.

https://doi.org/10.1016/j.system.2021.102469

Nunan, D. (2004). The connection between autonomy and communicative teaching. In M. Swanson \& K. Hill (Eds.), Proceedings of JALTCALL 2003 (pp. 715). JALT.

Pawlak, M. (2011). Anxiety as a factor influencing the use of language learning strategies. In M. Pawlak
(Ed.), Extending the boundaries of research on second language learning and teaching (pp. 149165). Springer.

Rigby, C. S., Deci, E., Patrick, B., \& Ryan, R. (1992). Beyond the intrinsic-extrinsic dichotomy: Self determination in motivation and learning. Motivation and Emotion, 16, 165-185. https://doi.org/10.1007/BF00991650

Ryan, R., \& Deci, E. (2000). Self-determination theory and the facilitation of intrinsic motivation, social development, and well-being. American Psychologist, 55, 68-78. https://doi.org/10.1037/0003-066X.55.1.68

Şimşek, E., \& Dörnyei, Z. (2017). Anxiety and L2 selfimages: The 'anxious self'. In C. Gkonou, M. Daubney, \& J.-M. Dewaele (Eds.), New insights into language anxiety: Theory, research and educational implications (pp. 51-69). Multilingual Matters.

Skehan, P. (1998). A cognitive approach to language learning. Edward Arnold.

Skehan, P. (2002). Theorising and updating aptitude. In P. Robinson (Ed.), Individual differences and instructed language learning (pp. 69-93). John Benjamins.

Sudina, E., \& Plonsky, L. (2021). Language learning grit, achievement, and anxiety among L2 and L3 learners in Russia. International Journal of Applied Linguistics, 172(2), 161-198. https://doi.org/10.1075/itl.20001.sud

Teimouri, Y., Plonsky, L., \& Tabandeh, F. (2020). L2 grit: Passion and perseverance for second-language learning. Language Teaching Research. Advance online publication. https://doi.org/10.1177/1362168820921895

Wei, H., Gao, K., \& Wang, W. (2019). Understanding the relationship between grit and foreign language performance among middle school students: The roles of foreign language enjoyment and classroom environment. Frontiers in Psychology, 10, 1-8. https://doi.org/10.3389/fpsyg.2019.01508 
Williams, M., \& Burden, R. (1997). Psychology for language teachers. Cambridge University Press.
Yashima, T. (2009). International posture and the ideal L2 self in the Japanese EFL context. In Z. Dörnyei \& E. Ushioda (Eds.), Motivation, language identity and the L2 self (pp. 144-163). Multilingual Matters.

\section{APPENDIX}

\section{Interview questions}

Please take a look at these questions in English and be ready to answer these questions in English. You can bring your notes with you to the interview session but just to help remind you about the questions. Some of the questions may have the same answers-that's OK. (Try not to read your answers from your notes.)

1. What does it mean to be a diligent English language learner? What do you do to maintain your motivation to study English?

2. How do you keep your focus strong for studying English? Do you have any advice for someone who wants to learn English? Provide specific advice!

3. Explain how hard you have worked at studying English? Why don't you give up?

4. How long have you loved English? What keeps you excited about studying English?

5. Were there some events in the past that fueled your love of English? Please talk about them.

6. Were there any people in your past that fueled your love of English? Please tell us how they influenced you.

7. Were there any English teachers that you have had or that you even have now who encouraged your love of English?

8. Have you studied abroad? How has that affected your desire to study English? (If you haven't studied abroad, do you have a strong desire to study abroad? Why haven't you gone abroad to study?)

9. Do you have any 'dreams' about using English in the future? Explain those dreams.

10. Have you ever thought of studying English overseas? If you had enough money, where would you go? How long would you stay? Why would you go there?

11. There are many things that can compete with your interest in studying English. What is it about English that makes it attractive to you?

12. Talk about any obstacles you have overcome to reach your English goals—be specific. Why didn't you give up?

13. Does studying English ever become boring? What do you do to keep going if you start to get bored?

14. Is thinking about English frequently important to you or not so important? Why or why not?

15. Do you ever imagine yourself talking or even singing in English? What place do you imagine? Are you using English with native-speakers of English? Who are they?

16. What did you do to address your English weaknesses? What are you doing to address your weaknesses? Explain specifically how you address any of your weaknesses in English.

17. You see a couple in a grocery store having a problem understanding the cashier who doesn't speak English well. Would you try to help them even though you have never met them before? Why?

18. Describe a specific situation when you had to use a lot of English but you were able to achieve your goals. Explain in detail. How did this make you feel? 
19. Do you sometimes study English in your free time? Do you ever read or watch movies in English just for fun? Is this important to you? If you had more free time, do you think you would study English more? Why or why not?

20. If you had the chance, how would you like to increase your English language use (for example reading books, writing, chatting with others, watching movies, etc.)? Give specific examples if possible.

21. In your opinion, what skills are the most important to be a successful English language learner (for example grammar, reading, writing, listening, speaking, face-to-face interaction, etc.)? You can choose as many as you wish to talk about.

22. Getting high scores on standardized English tests (e.g., IELTs, TOEFL, TOEIC, EIKEN, etc.) is

a. Very important

b. Somewhat important

c. Somewhat unimportant

d. Not important

Provide a reason for your answer above.

23. Is getting a job that allows you to use English important to you? Why?

\section{Data excerpts}

\section{Perseverance}

Chirawan: I still have to learn new knowledge. So I sometimes I think that how how much can I get closer to be like to be good at something other than in Thai. Like how how long will...does it take to mainly be good at English? Like. Like, understand everything that they said, don't have to look up on a dictionary. Yeah, sometimes I just want to give up, but I never would give up. It's maybe because of my personality too.

Malee: ... it cannot be denied that I also have a very hard time with some kind academic tough lesson. But I try to think that I...they are parts of what's gonna help me reach the world success. So instead of giving up some difficult task, I more likely to try to look at some good points of them to push me out.

Dixia: I didn't give up. If I gave up with, I wouldn't be sitting here and answering the interview questions; I wouldn't be speaking in English, so I didn't give up. I was keep trying. I was practicing more, like I said, ah I had the need to study. So whenever I learn new words, I will write it down the meaning and I won't just keep it, I will try to use the word in a class, speaking to people, or when texting or in essays. I will try to use the word so that I won't forget it. So you have to practice more regularly. You need to practice and you need, you need to speak more. You need to speak to people ah in English and then you have to keep practicing. You shouldn't give up. And then ah until now I am not giving up. Until now, I'm learning; it's not that I I speak English perfectly. No, until now I'm learning English.

Mysha: I always daydream, always pen it out, so since then until now, I always journal. I feel like that make me improve my English because I would push myself to find new vocabularies all the time because I would always want my writing not to look boring. I'll always want my journal to have the pretty, pretty words. So I always pushed myself to find new vocabulary, which l'll ended ah up using it in everyday life. Ah reading books is also one of the things I would use to increase my English language. And uhm like I said, communicating with my friends. One of the reasons that I do to actually improve my English a lot. I never had someone communicate before except my sister now in uni I'm using English everybody. I'm learning new things or new vocabularies too, from all of them.

Emma: Every, yeah, every aspect of language has something to do with another. Like there is a connection between them. For example, I think ah I have to know grammar before I read or I write. Grammar is the basic of the language. But if I want to get familiar with the grammar, I would also have to read a lot, or listen a lot. Yeah. And uhm...and you, if you want to write good articles, it's also important to ah read a lot of others' good articles. Yes. And of course, you have to listen a lot, to, ah to speak like fluently or naturally. Yes.

Olive: EFL learner, it is one of the most important things to overcome the keep motivation when studying English. The reason I can keep my motivation to learn English is force myself into an environment of immersion education. The environment makes me practice to write down English lesson plans, or using English to teach my students in elementary school. Uhm, sometimes when I am tired of paying attention in English, the motivation keeps me going rather than stopping. Such as listening to English songs or broadcast instead of Chinese channels. To make sure every time when studying English should be efficient, I will let 
myself memorize the motivation every moment...let yourself surrounded by English. Except for practicing every day, trying to formulate a study plan. Decide how much time you are going to spend studying English a week and stick to it. Also, establish a routine.

Mariko: I had decided to write....keep, keep...record my, my life in the Philippines. So I decided to write diary. Yeah, because I want to. I want to. Look, I want to make my my life, whole life in English...so I didn't want to use Japanese because it, I think it's not help, help growing, my English skill.

Remi: I love I love studying English, so you know I have motivation and that the more I study about it, the more new things that I can find. That how I study or how.... better than before, so that makes me motivated a lot.

\section{Enjoyment}

Chirawan: I don't want to say it was really hard, but because I like—I love English, so I tried to make it fun and enjoy with with learning English.

Malee: I've always loved English. When I was young, I saw people who can speak other language, especially English, are very cool and very smart. That I've always been wanted to be like them, so ever since I was young, when I talked to foreigners and saw that they could understand what I said, it reminds me that what I learned, what I study was working. And I think that is what keeps me excited to learn more because I see that what I put my attention, my effort for works the way I wanted it to.

Dixia: ...they (teachers) actually encourage the students to love English like ah how to say like um the kind of activities they had in class, for example, like having drama. So we had to dress up like the characters and act in class. We have to memorize the scripts, so that was just the fun way to learn English, to study English, so...which make the students, including me, to actually enjoy the class and love the subject.

Mysha: I gained a lot of interest in novels and poetry and all those things. So for me, that was one of the things that ah made me very interested in... ah to keep me going in my English. I think since I was four, five, I think I've loved English from that. What keeps me exciting is I like to see new things, brand new authors, like I said before...

Olive: The reason I always have interested in learning English because I believe that language is culture, and culture is English... and culture is language. These two can't be separated. English has given me a better understanding of people who live in countries abroad. I can be more insight into how people think, live and work by using English. I love to learn cultural knowledge that is unique in a country. Also, I think if you understand which words are acceptable or unacceptable in a different country, this might save you from an awkward cultural misunderstanding when uhm when when you're talking your foreign friends and coworkers. Yeah, and I love the cultures.

Remi: Like it's beyond English, but he also he (an American friend) also makes me feel like, 'Oh I love English and I want to be able to be speak.' I want to be able to speak more and more.

\section{Curiosity}

Olive: ... if I see uh uh board or a sign, I'll think about, oh how should it said in English. And uh last weekend I went to a restaurant with my families and we saw the menus. And I think about, oh, how should I use English to uh to say these uh these dishes in English like uh [konsukaiku] and I think it's sweet and sour pork.

Mariko: I always try to talk to someone using new new word. And try again, try again.

\section{Anxiety}

Chirawan: We don't have to be like really stress on it like to make it stressful. It just a language. And I think you have to adapt it into your daily life like you can find it everywhere. And to make it become, you have to become closer to it. Don't think it is too far.

Malee: ...you don't have to push yourself to think about English all the times in all the aspects which with stress you out, but you just focus on your goal... 
Dixia: ...it's normal to make mistakes when you are learning a language and then you should umm how to keep your focus strong. OK, Learning English is not only about reading, writing, learning grammar, 'A' for apple, 'B' for ball, no it's not only that, you watch movies, English movies, TV shows, you can learn many things from that, you can learn new vocabularies and then you can communicate in English, although your English is not fluent . You have to try to communicate...

Olive: Sometimes I still feel discouraged and lack of confidence. I'm very grateful that you (her teacher) always gave me a lot of opportunities to increase every aspect of abilities in English.

Mariko: It became easier and I don't fear ah easier and I did it easier and, I don't feel afraid to use English, even even though my English is not good.

Remi: I wanna say, just do it (laugh) and if you wanna speak English, you should and if you wanna read you should read, so just do it.

\section{Boredom}

Chirawan: Like sometime I said, oh, no, I'm not going to watch English movie because it is enough. I don't want to hear any English anymore. And I don't wanna speak English anymore. But I take a rest and then I come back to it. After I like.

Malee: I think I only get bored in English when a teacher makes it boring, for example, explaining very hard topics but doesn't really justify how it's going to be applied in real life situation. And that makes me feel like, 'Why do I need to know this?' And that is what makes it boring, I think. And as I said, I try to keep it going by thinking that it's a part of what's going to help me have a rounded ability in English.

Mysha: I would like to keep myself entertained. Ah, well, I'm studying English. Like for some people, it can be a boring subject. But when you focus uhm for like example, so how do you say this when you take part and be interactive, it is actually more fun to learn English rather than just doing all the exercises and grammar and stuff...... Sometimes it does because ah grammar and all those things. It's actually there is a lot of rules in English that you have to follow. Ah, subjects like phonetics. I'm not that inclined with it, ah it does get boring at times. It does get difficult. But, you yeah I just keep going.

Olive: At that time I read the Hunt for Red October, because of the difficulty of the narrative way. I think one of the reasons I nearly gave up reading was I once felt that English made me so frustrated. That also made me bored at keeping reading that book written in English.

Emma: So no. It's never boring...Maybe not, maybe not really interesting, but it's not boring. So I think it's because I just watch a lot of like TV series, movies and interviews. I think it's how I study English. Yes.

Mariko: (Does English ever get boring?) Never!

\section{Extraversion versus Introversion}

Chirawan: Or even when you go to. Out when you go outside, you can see many foreigner out there some time they want help from you because you are an English major student, so I'm pretty sure you can help even though your grammar is not like hundred percent correct, but. You can help them with your skill...... always help people. Like even strangers, I know because I want to use my knowledge to help others. (Claimed introversion)

Dixia: I would ask my friends for help, like how do you say, how to put it in words, like for example. So my friends they will help and if they have any problems I will help them. Yeah. So this how we learn each other until now in university.

Malee: (When asked about helping an unknown foreigner who is struggling with the local language) Of course, I would try helping them, even though I've never met them before, because I know I can help. So why wouldn't I? I don't want to just stand in the line waiting there, knowing that I can help. I mean, if I be under that situation like them, it would be so nice to have someone help me, so I would definitely help them.

Mysha: So when I joined uni, I found a group of friends who I actually can use English with them. With that way, I am improving my English $\mathrm{H}$ because one of the good ways to improve English is my communication. So as I'm communication....as I'm communicating, I'm improving my English all at once, yeah. (Claimed introversion)

Emma: (When asked about helping an unknown foreigner who is struggling with the local language) So I think yes, I would definitely help them. And the reason is because I was ah helped in Germany before. Yes, we were buying, we wanted, we 
wanted to buy alcohol in Germany because, you know, in Germany, we can buy alcohol when we were ah 16 ? Yeah, we can buy and we want to buy some alcohol in the store. And then the...the...the what, the clerk he, the cashier, he asked us to show yeah show ID, but he said in German, so we couldn't understand. The stranger just came in, told us in English that, oh he, he just want us to show his, show him our ID...... Ah, I would like to have opportunities to chat with foreigners and make friends with them. Yeah.

Mariko: Yes, actually, um, I like I like talking to Eng...native teacher in university in [university name omitted] also you (her teacher) so it keeps me studying English.

\section{Vision of English}

Chirawan: I didn't want to be in a teacher since I was young, but I don't know why these days I just want to be an English teacher, just like those like my mom said when I was young. I didn't just want. I am not even sure. Do I really want to be a teacher or something else? But after I study a lot... a lot...in English, and I feel like maybe I can like expand my knowledge and help others so my dream may be English teacher. I'm still sure...... actually I want to study other thing. But English is important, like and you and I don't get any any other chance that much chance like they think that why why you study other things that is not important, right? English is important in our country. So I have to try hard on English even though I want to study other things, but I have to focus on this first.

Malee: ...to find yourself a goal when you study like ask yourself why or what are you doing it for? And by doing that, I believe it would automatically provide you a strong focus for your English study...... Well, you know, I can still hear the dreams of of using English in the future. Well, I used to dream of working as an interpreter, but later I found it I found it kind of boring . So recently, I'm kind of interested in the business of hotel and hospitality. And I'm, I'm right now consulting with my agency to applying for the internship program in the United States. And if everything goes smoothly, I am going to be trained in a position of the front desk for a year there. And hopefully I can find some way to be employed and work there permanently. And I think that's that's the current dream of mine in using English in the future.

Dixia: I can give like interview for a job job interview. It's very important. Ya know? Like ah speaking English explicitly allows you to broaden your world and...from job opportunities to the ability to relate to people from different culture, from different countries. So I think writing, speaking and face to face interaction are the most important things...

Olive: It is not so important to have a job that uses...that uses all English. Because I will use my free time to enhance my language ability! Uhm, I think uh English is a language and language is ah is used to communicate, communicate, so uh if I ' $\mathrm{m}$ in ah un if I am in an environment that use...that needs to use English, I will try my best to use, but uh if there were no chance to use English on the job I think that will be OK too because I will use my free time to enhance my English.

Mariko: Actually, I usually watch English movies and I always remain--my dream. I want to work using English. OK, so it's my motivation...... actually, English is global language, right? So if I can speak English, I can stay everywhere. I can go everywhere. I can talk to every...everybody.

Remi: So for my job, of course, I want to use it. And like I want to work with Japanese and English cuz my first language is Japanese. I also like at some point I want to work in another countries and I can use English as a like language and the tool. So it's kind of, I'm still thinking about it, but I really want to use English or if it's possible, I want to use it 24/7.

\section{Events}

Chirawan: So I thought that I didn't know what I was actually good at. So I tried to find myself and I found that it was not in. It was not math and science. So I changed my path to English and after I study more and study harder and I got good grades. So it was kinda good memories that I got. Good point, after I try hard. I think it was expected that what I did, what I try. So I kept learning after I got good points from the examination since eighth grade. (good grades)

Mysha: Besides only being a communicative language in my house. One of the things that pushed me for my love for English is reading. (love of reading and communication in the $L 2$ )

Emma: I watched ah a TV series called The Hollow Crown ah when I was 16, in high school. And the series was based on William Shakespeare's history dramas, history plays, ah Richard II, Henry IV, and Henry V. And ah it's...like...I was really fascinated by Shakespeare's words. And it's like the first time that I felt that language is beautiful, like English is very beautiful. (TV drama) 
Olive: I remembered there was an English song competition when I was in junior high school. That was a great time because all the classmates in class automatically spoke in English and practiced the song we selected to sing in the competition. Ah, exactly the time is around Christmas, we are just like staying in the environment or English-speaking country abroad! (English song competition)

Remi: OK. So, yeah, I had some events at like Halloween or Christmas at language school and we could talk about anything we want, so it wasn't like a lecture and I could talk about our lives or like everything and I could convey what I wanted to say. And teachers also understood what I said. So like those understanding each other made me love English more. (free talking at holiday events)

\section{Personal encounters and L2 teachers}

Chirawan: I was hundred percent sure that it was my mom because I live with her. She is a single mom and she. Her dream was to be an English teacher and she kinda tell me all the times, in like...I can recall that she want to be English teacher, but she cannot because, grandpa, didn't let her to be. And yeah. And is kinda something that was in my head already in my head. And I just started because like she said, she was not good at math and she didn't teach me anything about math. So when I have when I had English homework and she can teach me and she made me understand better. And since then I got used to it....... I had one teacher, when I was in eighth grade. Yeah. It's when I started to love English. She she taught me like she encourages me that Ice. My name is Frozen (pseudonym nickname), right. And she said, Frozen I know you can do it when I didn't even sure that I wasn't sure that I I really can manage this thing. But she encourages me that I know you can do it. You are good at it. And it made me like. Be sure to myself that, oh, maybe I was good at. Studying English, so she supported me. And she gave me the chance to go study abroad. (mother and $8^{\text {th }}$ grade $L 2$ teacher)

Malee: Uh, honestly, no. I couldn't think of any specific teacher who would have encouraged me. I mean, every teachers are kind of like, same to me. I respect them. I appreciate them. But no one so far has a very strong or an outstanding influence on me. (no one)

Dixia: I think no one actually influenced me to love English. I started to love English by myself. But like I said, umm my teachers. Without them, I think I wouldn't have no ah learned English uh spoke English that fluently. So I think ah teachers, they play important role in this, but they didn't influence me to love English. I love English by myself because of the activities we had and all that because of the cartoons I watched, the movies I watched and all that. (no one)

Olive: I had to thank my roommates in university. They encouraged me to apply a work and travel plan in USA. I successfully went to the USA and took two part-time jobs in Grand Canyon National Park..... OK uhm I I want to thank my advisor in the institute have always cheer me until now......I'm very grateful that you always gave me a lot of opportunities to increase every aspect of abilities in English. My English proficiency got improved, attributing the encouragement to you, yeah. (her roommates and her current advisor/the interviewer)

Emma: No, I think no. (no people mentioned and no L2 teachers of influence)

Remi: ...but I found my favorite artist or singer that I really liked and they are from the UK and that I mean, they gave me motivation to study. So after that I really I studied a lot, but. They gave me motivation. So it was like automatically...Everyone is kind of hating them, but do you know One Dir... One Direction?...... Ahh, Yes, I have one. And I met him in the US while I'm in I'm staying abroad. Yeah but he's studying Japanese, but his first language is English. But For me, first, first language is Japanese. And I was studying English over there. So like I was motivated by his attitude for studying Japanese. It's like it's different language, but same things to to learn about second language. So he gave me I mean, he still gives me motivation...... It's so long and he's he's not teacher anymore, but for me. But he works different language school in Nagano, so he still keeps in touch with me. Like, how's it going? And school life. And, umm, of course, how he taught me was great. Arre? I don't remember that much cuz I was too young, but I just remember that was really fun to go there every Saturday. And also like he cares about students a lot. So I like how he acts and gives us makes me feel like. Like it's beyond English, but he also he also makes me feel like oh I love English and I want to be able to be speak. I want to be able to speak more and more. (UK band, American friend and elementary teacher) 